\title{
Structure Design and Bearing Capacity Analysis for Crawler Chassis of Rice Combine Harvester
}

\author{
Zhong Tang ${ }^{\mathbb{D}}$, Hui Ren, Xiyao Li, Xin Liu, and Biao Zhang \\ School of Agricultural Equipment Engineering, Jiangsu University, Zhenjiang 212013, Jiangsu, China \\ Correspondence should be addressed to Zhong Tang; tangzhong2012@126.com
}

Received 11 September 2019; Accepted 13 April 2020; Published 4 May 2020

Academic Editor: Mojtaba Ahmadieh Khanesar

Copyright (C) 2020 Zhong Tang et al. This is an open access article distributed under the Creative Commons Attribution License, which permits unrestricted use, distribution, and reproduction in any medium, provided the original work is properly cited.

\begin{abstract}
Due to the current unstable travel performance and poor driving maneuverability of rice combine harvester crawler chassis with high load in the rice field, the driver's standard sitting posture model was developed by analyzing the handling of the crawler chassis driving control panel. Based on this model, the joystick length and cab manipulation space layout were designed. The Finite Element Software was used to develop the loading and restraining model of the chassis frame, and then the structural characteristics and bearing capacity of the crawler chassis were analyzed. The high-bearing running stability and the rationality of operating force of the joystick of rice combine harvester crawler chassis designed in this paper through experiments were verified by experiments. The results showed that when the crawler chassis of rice combine harvester bears a load of $3.5 \mathrm{t}$, the driving speed is relatively stable in the three speed ranges of $1 \mathrm{~m} / \mathrm{s}, 1.5 \mathrm{~m} / \mathrm{s}$, and $2 \mathrm{~m} / \mathrm{s}$, and the maximum variance of driving speed variation is $5.022 \times 10^{-4}$. The actual average operating force of each operating lever on the crawler chassis ranges from 30.36 to $42.71 \mathrm{~N}$, and the operating force of each operating lever is suitable for $95 \%$ of Chinese adult male operators. The research results provide a good method and reference for the future development of the crawler chassis structure of rice combine harvester.
\end{abstract}

\section{Introduction}

In the process of rice harvesting, rice combine harvester, as an important tool to improve the harvest efficiency of rice, can effectively reduce the labor intensity of farmers and improve the harvest efficiency [1]. In addition to the higher requirements on the working performance of the working device, the rice harvesting also puts forward higher requirements on the field pass ability, operational reliability, and operation simplicity of the crawler chassis [2]. At present, there are many kinds of crawler rice combine harvesters in China, but the cab is lack of ergonomics design, and the driving control structure is poor in adaptability. Therefore, it is urgent to develop the cab and chassis structure of the rice combine harvester which is suitable for the majority of adult male operators in China.

When crawler chassis is driving in the field, problems such as poor crossing performance and unstable walking under high load due to the interaction between crawler and soil often exist [3]. To this end, Sojka and Cornak proposed the theoretical mathematical model of the vibration problem of tracked vehicle by studying the interaction between the chassis components and the vehicle body during the running of the tracked vehicle. The research provides a reliable theoretical basis to design the track of the vibration-damping structure [4]. Liu et al. proposed a wheel-rail adjustable steering mechanism based on steering mechanism and parallel quadrilateral mechanism, determined key variable and calculation method of steering error, and designed an adjustable wheel-rail agricultural chassis to overcome the defects of poor steering performance and flexibility of agricultural chassis [5]. Sutisna et al. adopted the vehicle model of the rice combine harvester with crawler differential steering to study the steering control performance of the rice combine harvester [6]. $\mathrm{Lu}$ and $\mathrm{Lu}$ designed a differentia reversal to caterpillar chassis; the caterpillar chassis braking system has a simple structure, has flexible use, assemble, and disassemble because it has good braking effect, and solves the problem of small crawler chassis braking better [7]. To improve the caterpillar chassis walking and brake 
performance, Li et al., designed a chassis and gearbox mechanism that can realize three kinds of steering modes, such as differential reverse steering, differential steering, and single-side brake steering. Their results improved the flexibility of the combine harvester in the field, and overcome the defects of large steering area and large steering resistance caused by the single-side braking method of the traditional crawler chassis [8]. Li et al. proposed a new hydraulic viscous drive (HVD) power drive system to realize stepless speed creep without affecting the service life of the combine harvester drive system, improving the driving comfort of the combine harvester [9]. Xia and Sun proposed a new type of stepless transmission (CVT) system, which adopts a stepless speed-regulating power cycle hydraulic mechanical transmission structure, thus obtaining a large torque ratio at zero speed ratio and improving the transmission efficiency of the rice combine harvester [10]. The crawler chassis has always been the focus of research by many scholars. A variety of crawler chassis structures have been developed for different walking environments and chassis structures. However, there are few reports on the development and design of the rice combine harvester.

There are many research studies on caterpillar chassis of combine harvester in vibration and braking ability. However, the design still lacks relevant theories and data of ergonomics design, which leads to some problems such as poor operating comfort. In view of the design of a control layout of crawler chassis is unreasonable and prone to problems such as driving fatigue and misoperation, Lidiane and Joao through the ergonomics work analysis (EWA) and Wisner's human body hypothesis for Australia compared with the sugarcane harvesting machinery and its operation in Brazil, and the mechanical structure and the change of the operating space caused by different human variable are proposed [11]. Qiu et al. conducted a survey of the satisfaction of tractor drivers on the function and interface usability of driving operations [12]. Han et al. analyzed the characteristics of the manual take-up operation, designed the structure of the edible sunflower harvester, analyzed the travel distance of rod stroke, and designed the rod length variable in combination with transmission angle conditions [13]. Lee et al. designed a small combine harvester based on Korean human variables, making the operating space suitable for most Korean operators [14]. In order to improve the manipulator's handling of agricultural machinery, Wang et al. designed the joystick length and maneuvering space layout and completed the optimal design of the combine harvester based on driving comfort through the driver's sitting posture simulation and control panel access control sexual analysis [15]. In order to solve the problem of poor performance of agricultural machinery in the orchard operation in hilly areas, Wang et al. and other researchers have designed a triangular track-type orchard power chassis with simple operation, good stability, and climbing performance [16].

At present, there are many research studies on crawler chassis, but the existing crawler chassis still has problems such as poor passability in rice fields, unstable operation at high load, and poor driving maneuverability. For this reason, this paper completes various operations through ergonomics. Design of the control space layout of rod and $\mathrm{cab}$ is completed by mechanical analysis to complete the design of the track-related variables. After the meshing, the Finite Element Analysis of the chassis frame is carried out, and the bearing capacity is theoretically verified. By comparing and analyzing the data of high-load linear driving test, man-machine test of operating force of the operating rod, and theoretical design value, the rationality of crawler chassis of rice combine harvester designed in this paper is verified in terms of bearing capacity and maneuverability.

\section{Material and Methods}

2.1. Overall Structure and Working Principle of Crawler Chassis. The crawler chassis has good field passability and overall load-bearing ability. The rice combine harvester crawler chassis is mainly made of rubber track. The crawler chassis adopts the three-layer chassis structure, which can ensure the stability of the whole machine under the condition of large load [17]. A cab is designed on the crawler chassis of the rice combine harvester, which can realize the walking and steering control of the crawler chassis. Crawler chassis can be used for walking on complicated working ground such as rice field, and various crawler rice combine harvesters can be mounted to realize field operation. Crawler chassis of rice combine harvester designed in this paper is mainly composed of three major parts: rubber track, combine harvester cab, and chassis frame. The crawler chassis structure is shown in Figure 1.

The crawler chassis of rice combine harvester is a "four wheels and one belt" structure, which is mainly composed of a driving wheel, thrust wheels, a guiding wheel, a towing wheel or a tensioning wheel, and a crawler track $[18,19]$. The structure of the crawler chassis "four wheels and one belt" is shown in Figure 2.

When the crawler chassis is walking in field, the driving wheel is rolled up from the rear by the engagement between the gear teeth on the driving wheel and the track chain under the action of the driving torque of the speed reducer. The adhesion of the track under the thrust wheel to the ground forces the drive wheel to wind up the track, and the guide pulley lays the track to ground, allowing the body to run forward along the track.

2.2. Design of Main Variable of Crawler Chassis. Track support length $L$, track gauge $B$, and track board hanging width $b$ shall be reasonably matched to meet the requirements of grounding pressure ratio, adhesion performance, and turning performance. The initial weight of rice combine harvester is $4 \mathrm{t}$. According to the research results of reference [20], the empirical Equation for calculating crawler chassis is shown as follows:

$$
\begin{aligned}
& L_{0} \approx 1.07 \sqrt[3]{G}, \\
& L \approx L_{0}+0.67 h_{0},
\end{aligned}
$$

where $L_{0}$ is the grounding length, the unit is $\mathrm{m} ; h_{0}$ is the crawler height, the unit is $\mathrm{m}$; and $G$ is the weight of the machine, the unit is $\mathrm{t}$. 


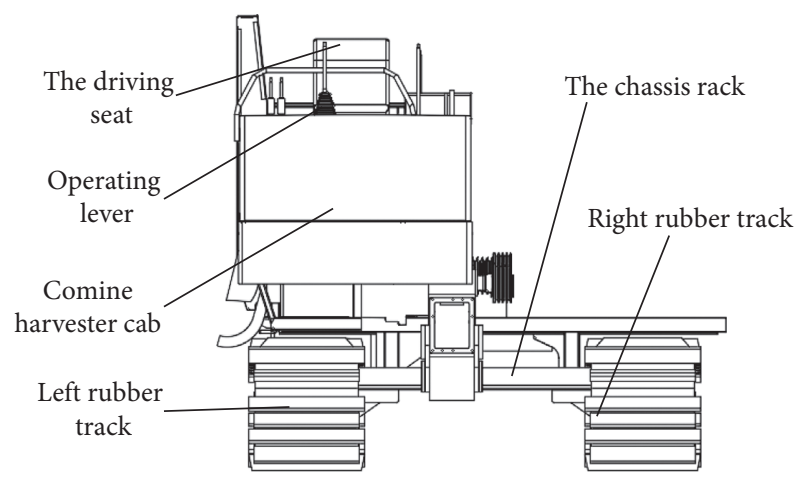

FIgURE 1: Schematic diagram of crawler chassis of rice combine harvester.

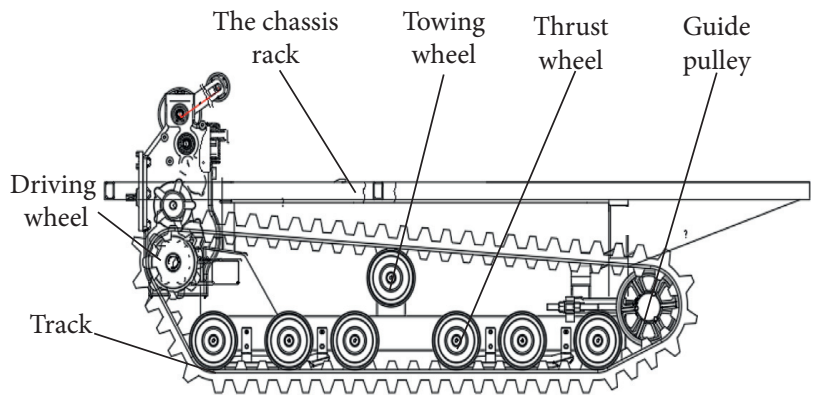

Figure 2: Structure of the "four wheels and one belt."

Let $G=4 \mathrm{t}$ into equation (1) give $L 0=1700 \mathrm{~m}$; taking $h_{0}$ as $470 \mathrm{~mm}$ and substituting equation (2) gives $L=1864.5 \mathrm{~mm}$. The ratio of the track grounding length $L_{0}$ to the gauge $B$ is generally between 1.2 and 1.4, and the boarding width $b$ and the grounding length $L_{0}$ are generally between 0.18 and 0.22 . From the abovementioned ratio relationship, $B=1307 \mathrm{~mm}$ and $b=340 \mathrm{~mm}$.

The track pitch $t_{0}$ and the number of drive wheel teeth $z$ should meet the strength and stiffness requirements. In this case, try to choose a small value to reduce the track height.

According to the relationship between the pitch and the weight of the whole machine,

$$
\begin{aligned}
& t_{0}=(15 \sim 17.5) \sqrt[4]{0.001 G}, \\
& L^{\prime} \approx 2 L_{0}+\frac{z t_{0}}{2}+\left(\frac{1}{2} \sim \frac{2}{3}\right) t_{0}+2 \Delta,
\end{aligned}
$$

where $L^{\prime}$ is the full length of the track, the unit is mm; $T_{0}$ is track pitch, the unit is $\mathrm{mm}$; and $z$ is the number of driving wheel teeth.

Substitute $G=4 \mathrm{t}$ into equation (3), then $t_{0}=127 \mathrm{~mm}$; take $z=6$, substitute $t_{0}=127 \mathrm{~mm}$ and $L_{0}=1700 \mathrm{~mm}$ into equation (4), and then $L^{\prime}=3906.1 \mathrm{~mm}$.

According to the research results of reference [21], the average ground pressure ratio of crawler chassis is usually $50 \sim 58 \mathrm{kpa}$, which is an important technical variable of crawler chassis. It directly determines the passability and stability of crawler chassis structure and is also a decisive condition for the research on the adhesion torque between crawler and ground. In this paper, $50 \mathrm{kpa}$ is adopted, and the track ground area is determined by the track load quality and average ground pressure, as shown in the following equation:

$$
\begin{aligned}
& A \geq \frac{G^{\prime}}{P}, \\
& A=2 b L_{0},
\end{aligned}
$$

where $b$ is the track board hanging width, the unit is $\mathrm{m} ; G^{\prime}$ is chassis bearing weight, the unit is $\mathrm{N} ; P$ is the average grounding voltage ratio, the unit is pa; and $A$ is the ground area, the unit is $\mathrm{m}^{2}$.

Let $G^{\prime}=\mathrm{Gg}=9.8 \mathrm{G}=39200 \mathrm{Nbe}$ substituted into equation (5), and $b L_{0} \geq 0.392 \mathrm{~m}^{2}$ can be obtained by combining the two equations (5) and (6).

According to the calculated and actual data, the track hanging plate width $b$ is $340 \mathrm{~mm}$, the grounding length $L_{0}$ is $1700 \mathrm{~mm}$, then the total length $L^{\prime}$ is $3900 \mathrm{~mm}$, and the fullload average grounding pressure ratio $P$ is $33.9 \mathrm{kpa}$.

The drive wheel segment circle radius $r$ is an important variable to calculate the performance requirements of crawler travelling devices, such as Mr and Max. The design variables of the driving wheel are mainly determined by transfer power and travel speed. When designing the belt pulley, adding the number of gears can determine the meshing tooth number when the track moves correspondingly, so as to ensure the meshing uniformity of the track and improve the overall dynamic performance. However, it also increases the overall size of the drive wheels and adds height to the chassis. Therefore, the number of driving wheel teeth $z$ in this paper is 6 . Then, the calculation equation of the drive wheel segment circle radius $r$ is as follows:

$$
\begin{aligned}
D & =\frac{t_{0}}{\sin (180 / z)}, \\
r & =\frac{D}{2},
\end{aligned}
$$

where $D$ is the drive wheel diameter, the unit is $\mathrm{mm}$, and $r$ is the drive wheel pitch circle radius, the unit is $\mathrm{mm}$.

Let $z=6$ and substitute $t_{0}=127 \mathrm{~mm}$ into equation (7) to get $D=254 \mathrm{~mm}$. Then, substitute into equation (8) to get $r=127 \mathrm{~mm}$.

\subsection{Development and Design of Rice Combine Harvester Cab.} The cab of crawler chassis is mainly composed of a driving seat, a central bedplate, a side control panel, and various joysticks. The crawler chassis of track designed in this paper is shown in Figure 3. From the Chinese adult male body size and sitting size, the size, stroke, and steering angle of the operating levers are reasonably designed. Based on the ergonomics theory, the relative position of the joystick suitable for the majority of Chinese adult male operators was designed, and the layout optimization analysis of humanmachine control interface cab was carried out $[22,23]$.

2.3.1. Design of Operating Lever. The operating levers of the rice combine harvester are divided into two categories according to their structure and principle, small switch 


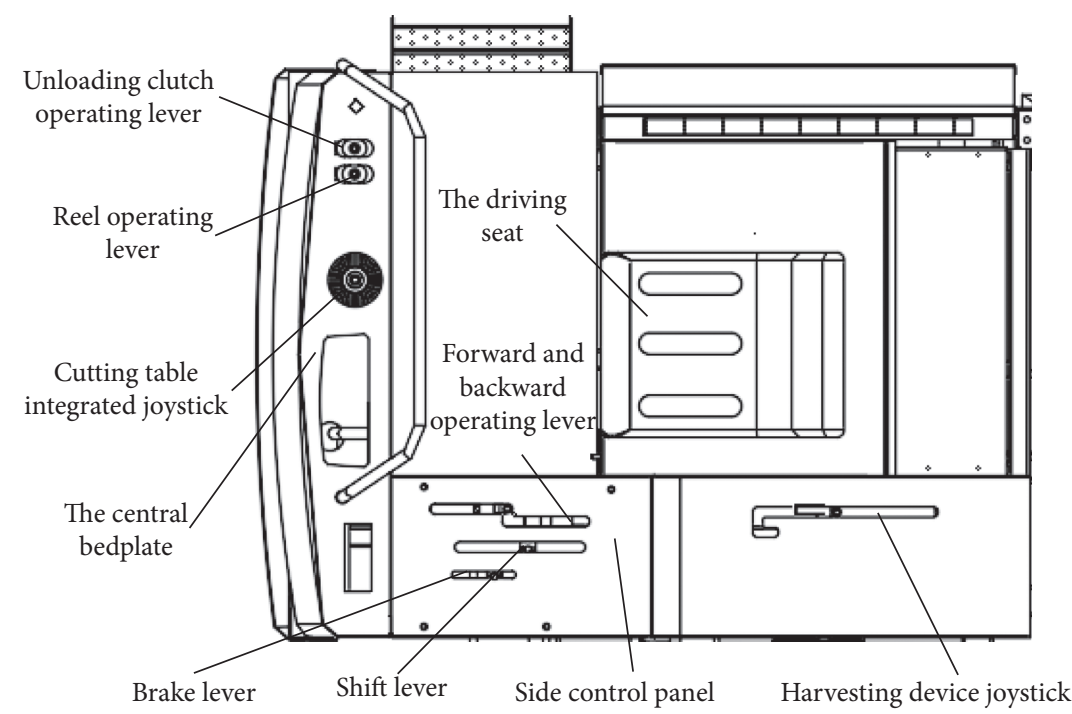

Figure 3: Top view of the combine harvester cab.

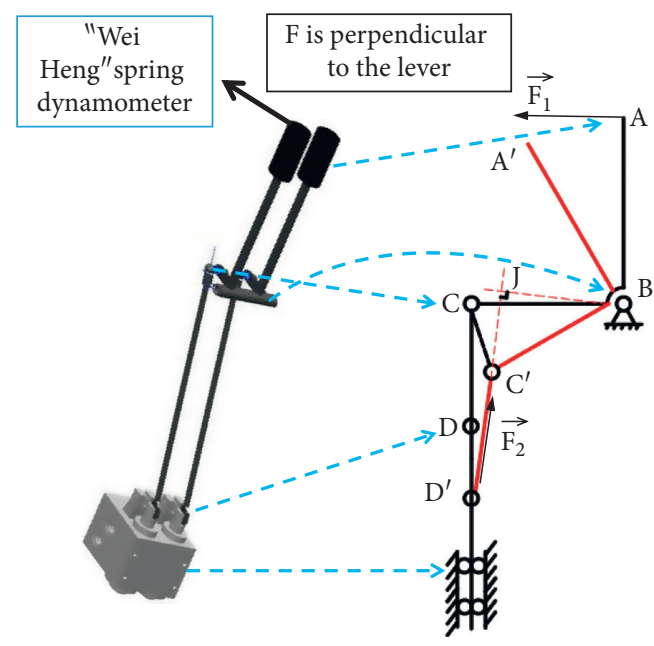

FIGURE 4: Small switch travel of the reel and principles of the operating lever.

stroke, and large switch stroke. The small switch stroke is like the reel lever and the header control lever [24]. The structure of the lever and the principle of simplified operating lever are shown in Figure 4.

By querying the relevant variable of the existing valve body, it can be known that the stroke required for the valve body switch connected with the unloading clutch lever, reel operating lever, and brake lever is $10 \mathrm{~mm}$, and the stroke of the valve body switch connected to the forward and backward operating lever is $20 \mathrm{~mm}$. The valve body switch connected to the shift lever is required to have a stroke of plus or minus $35 \mathrm{~mm}$, the stroke of the valve body switch connected to the cutting table integrated joystick is $20 \mathrm{~mm}$, and the stroke of the valve body switch connected to the harvesting device joystick is $80 \mathrm{~mm}$.

Structure of the rod shown in left part of Figure 4 is simplified to the linkage mechanism shown in right part of Figure 4. Through the analysis of the model, the required manipulation angle of the rod member when the corresponding valve body switch is completed can be obtained. Manipulate the amount of displacement.

Set the length of the $C D$ rod up and down displacement $D D^{\prime}$, that is, the switch stroke is $c$, and set the rotation angle of the rod during the work is $\theta, B C=l_{2}, C D=l_{3}, \angle A B A^{\prime}=$ $\angle C B C^{\prime}=\theta$, where $\theta$ is the designed.

In $\triangle C B C$, the triangle is an isosceles triangle, where $B C=B C^{\prime}$,

$$
\begin{array}{r}
H D^{\prime}=l_{3}-l_{2} \sin \theta+c, \\
2 l_{2}^{2} \cos \theta+2 l_{2}\left(l_{3}+c\right) \sin \theta=2 l_{2}^{2}+c^{2}+2 l_{3} c .
\end{array}
$$

According to the weight value and priority of the human-machine interface of the rice combine harvester, we should pay more attention to the design of the joystick in the cab. According to relevant studies [25], priority sequence and weight values of main joystick parts in each cab are shown in Table 1. We can conduct comparative analysis on the rationality of theoretical design of the joystick based on the priority of joystick.

In order to analyze and design the operating force of operating levers later, the switch stroke $c$ of the bar members and the length $l_{2}$ and $l_{3}$ of the operating levers can be obtained from the previous paragraph. By putting them into equation (9), the rotation angle $\theta$ of the main operating levers in the cab can be calculated.

In the case of designing $l_{2}, l_{3}, \theta$, and other variable of each lever, the length of the hand holding part of each lever is set according to the simplified mechanical analysis of the operation process of the joystick and the optimal operation force of the hand. Relevant studies show that the minimum operating force of the back of the human hand is $10 \mathrm{~N}$, and if the operating force of the hand is less than $10 \mathrm{~N}$, the controllability is not good. The maximum front and rear operating force of the hand is $130 \mathrm{~N}$, and when the operating force is greater than $130 \mathrm{~N}$, the controllability exceeds the 95th percentile adult male hand operating force in China. 
TABLE 1: Weight value and priority of each component of human-machine interface of combine harvester cab.

\begin{tabular}{lccc}
\hline No. & The evaluation object & Frequency of utilization \% & Priority order \\
\hline 1 & Unloading clutch operating lever & 3 & 4 \\
2 & Reel operating lever & 80 & 1 \\
3 & Forward and backward operating lever & 5 & 3 \\
4 & Shift lever & 10 & 2 \\
5 & Cutting table integrated joystick & 1 & 5 \\
6 & Harvesting device joystick & 1 & 6 \\
\hline
\end{tabular}

According to the research results of reference [26], the optimal average arm operating force of Chinese adults is $40 \mathrm{~N}$, the maximum left-right operating force of a handle is $90 \mathrm{~N}$, and the optimal average arm operating force from left to right is $30 \mathrm{~N}$. Based on the following mechanical analysis, we complete the design of various joystick lengths.

Since the operation process is a variable force process, in order to simplify the calculation, the calculation is performed at two moments when the joystick is moved to the intermediate position and the final position. The direction of the operating force is always perpendicular to the rod, and the position at every moment between the movements to the final state is simplified to the equilibrium state. The frictional resistance $f$ only exists in uniform rod $B C$, and take $f$ for $80 \mathrm{~N}$. Let rotation angle be $\theta$, operating force $F_{1}$, the bottom connection body bar stress $F_{2}$, the length of lever $\mathrm{AB} l_{1}$, the length of lever $\mathrm{BC} l_{2}$, the length of lever $\mathrm{CD} l_{3}$, the switch travel movement GD $c$, and the length of lever BJ $l_{4}$. Let $\angle B C^{\prime} J=\theta_{1}, \angle B C C^{\prime}=\theta_{2}, \angle C D^{\prime} C^{\prime}=\theta_{3}$, and $\angle C C^{\prime} D=\theta_{4}$. Among them operating force $F_{1}$ of each operating lever is desired.

According to Figure 4, it can be known from the moment balance that

$$
F_{1} \cdot l_{1}=F_{2} \cdot l_{4}+f \cdot l_{2} .
$$

From the isosceles triangle BCC, we know that

$$
\angle B C^{\prime} C=\angle B C C^{\prime}=\theta_{2}=\frac{180-\theta}{2}, \quad \theta_{4}=\frac{\theta}{2} .
$$

In the triangle $\mathrm{CDF}$, according to the law of cosines, we can know that

$$
\theta_{3}=\arccos \left(\frac{2 l_{3}^{2}+c^{2}+2 l_{3} \cdot c-4 l_{2}^{2} \sin ^{2}(\theta / 2)}{2 l_{3}^{2}+2 l_{3} \cdot c}\right)
$$

In the triangle $B C^{\prime} J, l_{4}=l_{2} \cdot \sin \theta_{1}$.

From equations (10) and (12), we can obtain

$$
F_{1}=\frac{F_{2} \cdot l_{4}}{l_{1}}+\frac{f \cdot l_{2}}{l_{1}}=\frac{F_{2} \cdot\left(l_{2} \cdot \sin \left((180-\theta / 2)-\left(\arccos \left(2 l_{3}^{2}+c^{2}+2 l_{3} \cdot c-4 l_{2}^{2} \sin ^{2}(\theta / 2) / 2 l_{3}^{2}+2 l_{3} \cdot c\right)+(\theta / 2)\right)\right)\right)+f \cdot l_{2}}{l_{1}} .
$$

The component $F_{3}$ of $F_{2}$ in the vertical direction is the force required to open the valve body, so $F_{3}=F_{2} \cos \theta_{3}$. The magnitude of this value varies according to the valve body. The relevant data can be seen that the required force $F_{3}$ of the switch valve body is $40 \mathrm{~N}$. Thereby, the specific value of each joystick $F_{2}$ can be calculated, and the design value of the length $l_{1}$ of the joystick is finally completed. The results of the overall joystick design are shown in Table 2.

2.3.2. Cab Maneuvering Space Layout. Since most of the combine harvester operators are male, the overall design of the cab is based on the body size of Chinese adult males, but the design method of this paper is also applicable to the cab of female operators. Chinese adult body size is the main source of design data and size reference for this design [27]. The main dimensions of male human body in the 5th, 50th, and 95th percentiles of Chinese adult human body are shown in Table 2, and the sitting variable of the male human body in the 5th, 50th, and 95th percentiles of Chinese adult human body are shown in Table 3 .

In the actual design calculation, due to the influence of the workers' clothing, shoes, posture, and psychological factors, it is necessary to add an appropriate amount of correction to the design. The shoe wear correction amount is increased by $25 \mathrm{~mm}$ based on the measured value, and the dressing correction amount is increased, such as the hip width, by $15 \mathrm{~mm}$ on the basis of the measurement. In the actual situation, the operator mostly operates in a relaxed state, so a certain amount of correction should be subtracted from the standard of standing height and eye height.

According to the principle of ergonomics, the range of the upper limbs determines the range of the working space in the sitting position. Also, the comfortable working range changes with the height of the working surface, the distance of the hand from the center line of the human body, and the height of the hand. In addition, the range will be affected by the dress. Tables 2 and 3 can be designed, as shown in Figure 5 , for the 95th percentile adult upper limb horizontal working area in China. The design of the combine harvester cab has a design space of $1400 \times 1100 \times 1350$ cuboid.

\subsection{Chassis Frame Design}

2.4.1. Chassis Frame Structure and Bearing Variables. The chassis frame consists of four main beams, five main longitudinal beams, and auxiliary beams supporting other 
Table 2: Main dimensions of Chinese adult male human body ( $\mathrm{mm}$ ).

\begin{tabular}{lccccccc}
\hline No. & Percentile & Height & Weight & Upper arm length & Forearm length & Thigh length & Shank length \\
\hline 1 & 5 & 1583 & 48 & 289 & 216 & 428 & 338 \\
2 & 50 & 1678 & 59 & 313 & 237 & 465 & 369 \\
3 & 95 & 1775 & 75 & 338 & 258 & 505 & 403 \\
\hline
\end{tabular}

TABLE 3: Sitting variable of Chinese adult male human body ( $\mathrm{mm})$.

\begin{tabular}{|c|c|c|c|c|c|c|c|c|c|c|c|}
\hline No & Percentile & $\begin{array}{l}\text { Sitting } \\
\text { height }\end{array}$ & $\begin{array}{c}\text { Sitting } \\
\text { position } \\
\text { cervical high } \\
\text { point }\end{array}$ & $\begin{array}{l}\text { Sitting } \\
\text { eye } \\
\text { height }\end{array}$ & $\begin{array}{c}\text { Sitting } \\
\text { shoulder } \\
\text { high }\end{array}$ & $\begin{array}{c}\text { Sitting } \\
\text { cubits } \\
\text { high }\end{array}$ & $\begin{array}{l}\text { Sitting } \\
\text { thigh } \\
\text { thick }\end{array}$ & $\begin{array}{l}\text { Sitting } \\
\text { knee } \\
\text { height }\end{array}$ & $\begin{array}{l}\text { Leg to } \\
\text { foot } \\
\text { height }\end{array}$ & $\begin{array}{l}\text { Hip and } \\
\text { knee } \\
\text { distance }\end{array}$ & $\begin{array}{c}\text { Sitting } \\
\text { leg length }\end{array}$ \\
\hline 1 & 5 & 858 & 615 & 749 & 557 & 228 & 112 & 456 & 383 & 515 & 921 \\
\hline 2 & 50 & 908 & 657 & 798 & 598 & 263 & 130 & 493 & 413 & 554 & 992 \\
\hline 3 & 95 & 947 & 691 & 836 & 631 & 291 & 146 & 523 & 439 & 585 & 1046 \\
\hline
\end{tabular}

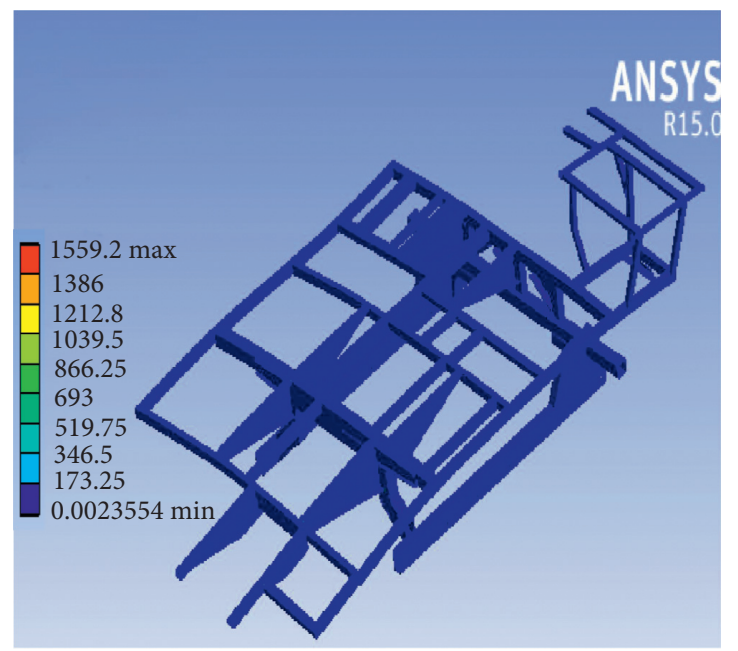

(a)

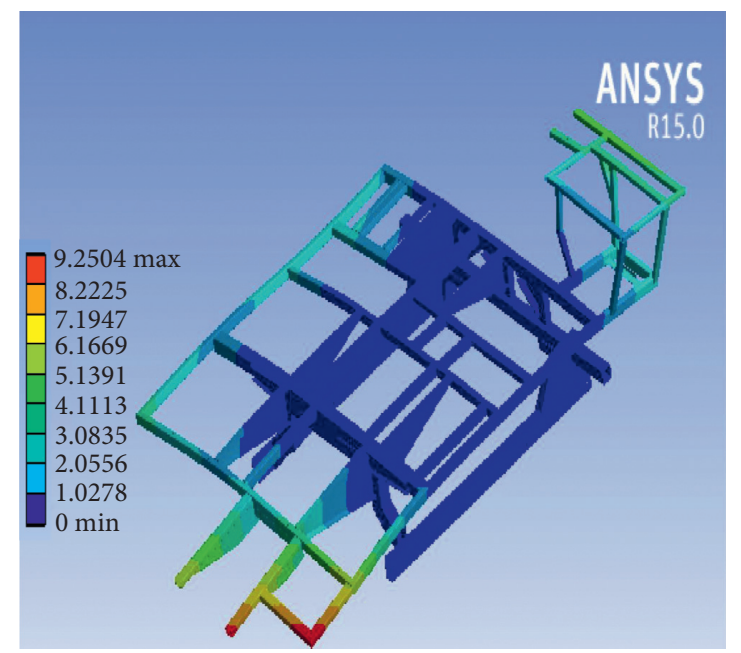

(b)

FIGURE 5: Low-speed full-load stress-strain diagram. (a) Equivalent stress diagram at low speed and full load. (b) Strain distribution at low speed and full load.

components, which are placed at the fulcrum of the main load such as the grain bin, threshing drum, engine, and bridge [28]. The chassis frame is made of $30 \times 30 \mathrm{~mm}$, $40 \times 40 \mathrm{~mm}$, and $40 \times 60 \mathrm{~mm}$ square tubes and rectangular tubes of different specifications. The thickness of the chassis is $2 \mathrm{~mm}, 3 \mathrm{~mm}, 4 \mathrm{~mm}$, and $6 \mathrm{~mm}$, and the connecting plate is used for fixing and strengthening. The entire rack is $3.807 \mathrm{~m}$ long, $2.163 \mathrm{~m}$ wide, and $1.036 \mathrm{~m}$ high.

The chassis frame adopts a 3-layer structure. The upper layer mainly carries the weight of the cab. The frame structure is used to increase the contact area with the cab so that the force is even, the stress and strain of the frame are reduced, and the bearing performance is improved. The frame is used for placing the hydraulic tank.

The middle of the chassis frame is the core of the entire chassis frame and carries the weight of the tank, threshing drum, grain bin, cab, engine, header, trough, and battery of the rice combine harvester. Therefore, the design is mainly supported by the supporting and strengthening effect of the horizontal longitudinal beam. The front end is the loadbearing part of the cab, engine, header, trough, and partial threshing device. The force conditions are complex, so three vertical beams and three triangular beams are added in the vertical direction to strengthen the connection, and one and the lower frame connected beams are welded. The bottom frame is connected to the tracked walking system.

The material of the whole frame is Q235, the thickness is $5 \mathrm{~mm}$, the elastic modulus $E$ is $196 \mathrm{GPa}$, Poisson's ratio is 0.25 , the safety factor is 1.2 , the density of low-alloy steel is $7850 \mathrm{~kg} / \mathrm{m}^{3}$, and chassis frame is obtained by Pro-E threedimensional modeling. The frame structure is shown in Figure 6.

Chassis frame mainly plays a bearing role. The load is mainly from 8 main aspects, grain box, cab, engine, oil tank, 


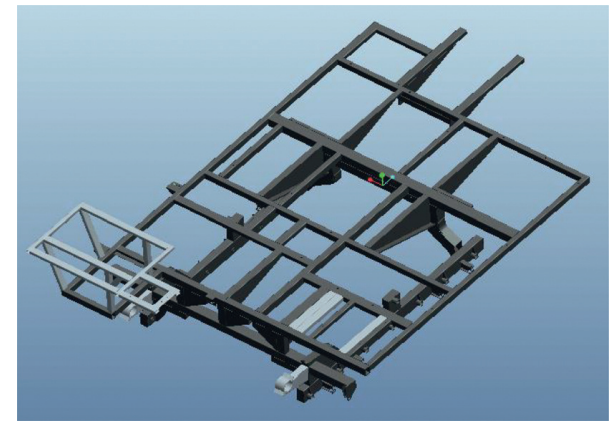

FIgURE 6: Modeling diagram of the chassis frame.

cylinder, threshing drum, and battery. The material of the whole frame is Q235, elastic modulus $E$ is $196 \mathrm{GPa}$, Poisson ratio $\mu$ is 0.25 , safety coefficient is 1.2 , and density of lowalloy steel is $7850 \mathrm{~kg} / \mathrm{m}^{3}$. The main component variables are shown in Table 4.

Mark the stress position of major components of crawler chassis, as shown in Figure 7.

2.4.2. Finite Element Analysis of Chassis Frame. In order to achieve static stress and strain analysis of the chassis frame, Finite Element modeling is required. In this paper, Pro/E is used to establish the 3D model of the chassis frame. In the $3 \mathrm{D}$ modeling process, in order to reduce the modeling workload and the complexity of the finite element model and improve the operation speed of the modal analysis, the model is simplified [29]. The simplified setting is based on the calculation accuracy: (1) regardless of the influence of welding on the vibration characteristics of the frame; (2) all process holes are neglected; (3) all chamfers and transition fillets are simplified to a right angle; (4) holes and small size structures in unimportant areas are ignored.

The mechanical structure of the chassis frame is mainly made of square steel, rectangular steel, and connecting plates. Prior to virtual assembly, the threshing rack is divided into different submodules: the bottom crawler joint rack, the middle support chassis rack, and the upper frame rack. After drawing the parts of corresponding submodules, virtual assembly of the thresher frame is carried out from bottom to top.

The built 3D model is saved in STP format, and then the material properties are defined by ANSYS 15.0 software [30]. The material selected for the chassis is Q235 steel, and its material properties are defined. The saved 3D model in STP format is imported into ANSYS Workbench, and Figure 8(a) is an import diagram of the chassis model.

Before the stress and strain analysis of the frame, the frame should be meshed to form a Finite Element composed of a finite number of nodes. The meshes of different sizes and shapes will have an important impact on the analysis results.

Meshing platform in Finite Element Analysis software can automatically divide mesh according to the mechanical structure. The following are several partition methods offered by Meshing platform [31], Automatic (Automatic grid partition), Tetrahedrons (tetrahedral grid partition), and Hex Dominant (hexahedral grid partition). Due to the complex chassis frame structure, automatic grid division is adopted and the chassis is adjusted to a grid size of $15 \mathrm{~mm}$. The gridded Finite Element Model of chassis after grid division is shown in Figure 9. After the grid division is completed, load and constraint are applied to the entity. Load is applied to each part one by one. The specific effect is shown in Figure 10.

As shown in Figure 10, $\mathrm{A}$ is the constraint imposed on the chassis frame; $\mathrm{B}$ is the oil tank load, the value is $999.6 \mathrm{~N}$; $\mathrm{C}$ is the threshing drum load, the value is $14818 \mathrm{~N}$; D is the grain box load, the value is $20827 \mathrm{~N}$; $\mathrm{E}$ is cab load, the value is $3116.4 \mathrm{~N}$; $\mathrm{F}$ is the engine load, the value is $3528 \mathrm{~N}$; $\mathrm{G}$ is the cylinder load, the value is $4226.88 \mathrm{~N}$; and $\mathrm{H}$ is the battery load, the value is $588 \mathrm{~N}$; the load application direction is vertical downward. Therefore, the stress-strain diagram of the chassis frame under the low-speed full load of the rice combine harvester is obtained. The results are shown in Figure 10, which can be further based on the total variables and equivalent stresses on the obtained cloud map. The carrying capacity of each part is analyzed.

2.5. Crawler Chassis Performance Test. The designed crawler chassis was installed on the rice combine harvester for real vehicle test. The load-bearing chassis was simulated by highload bearing when loading the counterweight $4 \mathrm{t}$, and the motion data under high-load pressure was collected and the chassis stability was carried out analysis. Through the spring balance method, the operating force of the joysticks designed in this paper under various conditions is measured. It is compared with the theoretical calculation value to analyze whether it conforms to the ergonomic design.

2.5.1. The Driving Stability of the Bearing Test. The common running speed range of the combine harvester is 0.25 to $1.5 \mathrm{~m} / \mathrm{s}$, so the driving speed of the gearbox in the three gears is designed to be $1 \mathrm{~m} / \mathrm{s}, 1.5 \mathrm{~m} / \mathrm{s}$, and $2 \mathrm{~m} / \mathrm{s}$. In order to verify the stability of processed crawler chassis under high load, it is necessary to test the straight speed of the harvester on the cement road surface. In addition, in order to simulate the actual movement of the harvester after bearing load, the harvester chassis is loaded on the frame by adding weight blocks until the total weight is $4 \mathrm{t}$. The total length of the test is $80 \mathrm{~m}$, of which the first $15 \mathrm{~m}$ is the acceleration and correction process of the harvester, the middle $50 \mathrm{~m}$ is the test data acquisition process, and the last $15 \mathrm{~m}$ is the deceleration and stopping process of the harvester. Three gear positions were tested separately. Five sets of tests were carried out at each gear position and the running time was recorded, which was converted into the running speed under high load. The methods of adding and weighting weight blocks to test the bearing and driving stability of the rice combine harvester are shown in Figure 11.

2.5.2. Operating Force Test of the Operating Lever. In order to obtain the working force of the hydraulic control valve, as shown in Figure 4, the resistance of the hydraulic control valve (measuring accuracy of $1 \mathrm{~g}$ ) was tested using a "Wei Heng" spring dynamometer. The test value is the mass (unit, 


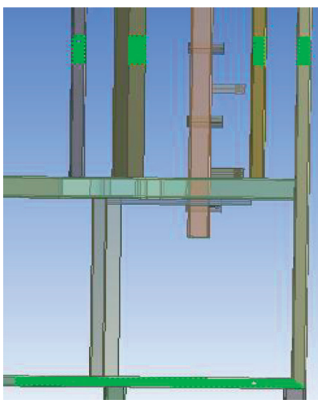

(a)

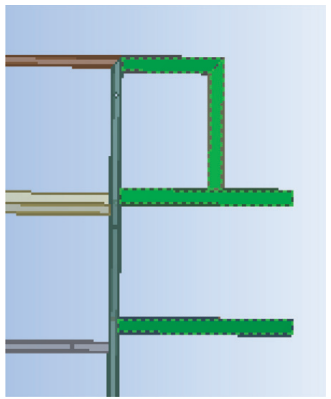

(d)

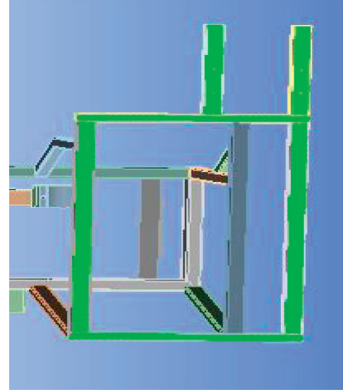

(b)

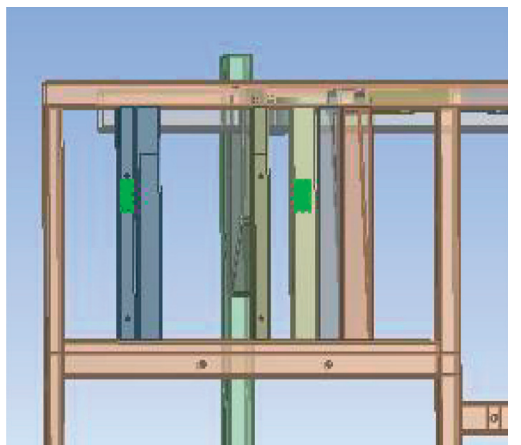

(e)

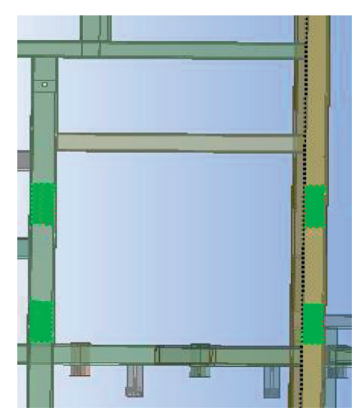

(c)

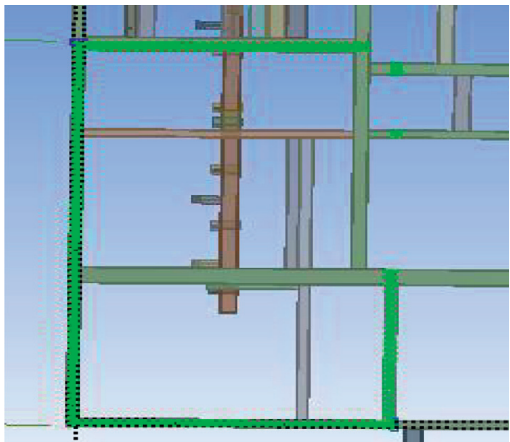

(f)

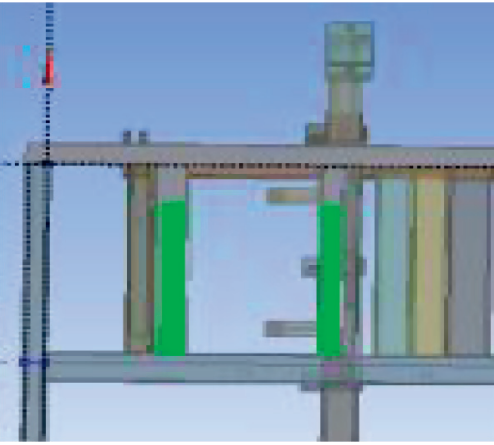

(g)

Figure 7: Marking diagram of the force parts of the main components of the track walking chassis. (a) Grain box bearing load mark diagram. (b) Cab bearing load mark diagram. (c) Engine bearing load mark diagram. (d) Oil tank bearing load mark diagram. (e) Cylinder bearing load mark diagram. (f) Threshing drum bearing load mark diagram. (g) Battery bearing load mark diagram.

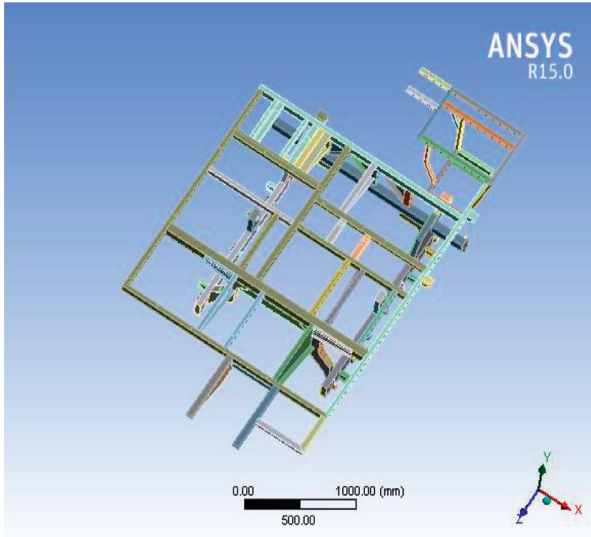

(a)

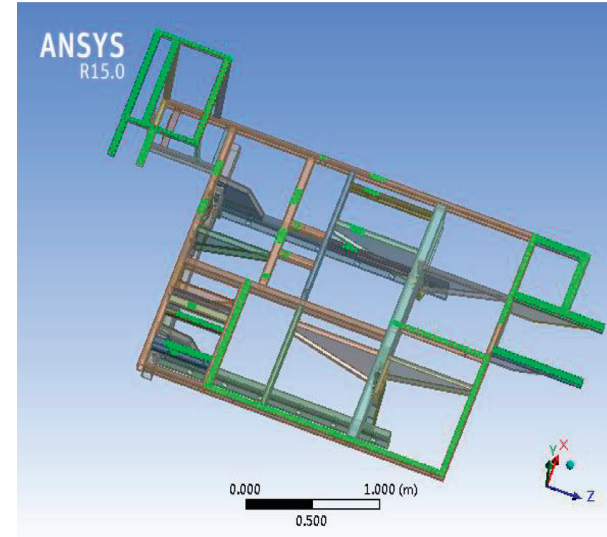

(b)

FIgURE 8: Crawler chassis frame model of ANSYS. (a) Imported chassis frame model. (b) Chassis frame bearing load mark diagram. 


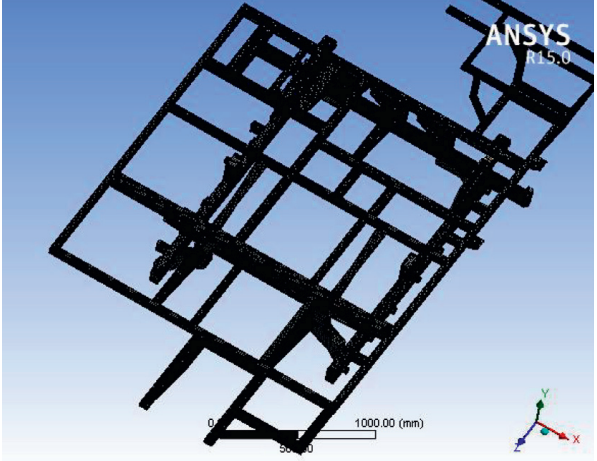

FIgURE 9: Meshing model of crawler chassis.

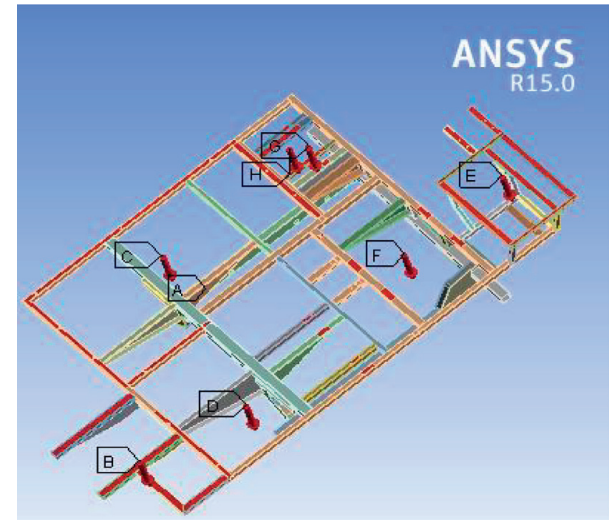

FIGURE 10: Load distribution on the chassis frame.

$\mathrm{kg}$ ), and the operating force (unit, $\mathrm{N}$ ) is the test value multiplied by 9.81 . During the test, the force of the lever should always be perpendicular to the lever. The test result is the maximum force that moves from the start point to the end point.

\section{Results and Discussion}

\subsection{Cab Variable Design of Crawler Chassis}

3.1.1. Results of Operating Levers Variable Design. The connecting rod variable of unloading clutch operating lever and the reel operating lever are $l_{2}=75 \mathrm{~mm}$ and $l_{3}=400 \mathrm{~mm}$, $c=10 \mathrm{~mm}$ is brought into equation (9), the rotation angle $\theta_{1}=7.66^{\circ} \mathrm{can}$ be obtained, and the displacement of the rod is $55 \mathrm{~mm}$. The connecting rod variable of the forward and backward operating lever are $l_{2}=45 \mathrm{~mm}$ and $l_{3}=270 \mathrm{~mm}$, $c=20 \mathrm{~mm}$ with the input equation (9), the rotation angle $\theta_{2}=26.44^{\circ}$ can be obtained, and the displacement of the rod is $182 \mathrm{~mm}$; shift lever's variable $l_{2}=180 \mathrm{~mm}$ and $l_{3}=680 \mathrm{~mm}$, $c=70 \mathrm{~mm}$ is brought in equation (9), the rotation angle $\theta_{3}=22.94^{\circ}$ can be obtained, and the rod displacement is $155 \mathrm{~mm}$. The connecting rod variables of the cutting table integrated joystick $l_{2}=65 \mathrm{~mm}$ and $l_{3}=410 \mathrm{~mm}, c=20 \mathrm{~mm}$ is brought in equation (9), the rotation angle $\theta_{4}=17.9^{\circ}$ can be obtained, and the displacement of the rod is $148 \mathrm{~mm}$. The connecting rod variables of the harvesting device joystick

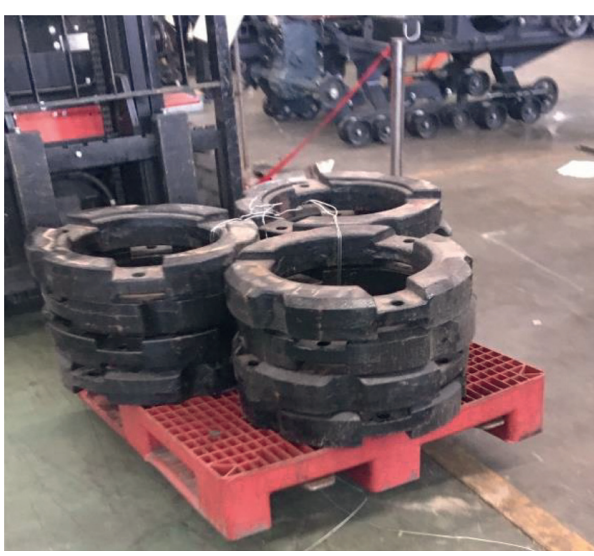

Figure 11: Counterweight block for driving stability of the rice combine harvester.

$l_{2}=95 \mathrm{~mm}$ and $l_{3}=480 \mathrm{~mm}, c=40 \mathrm{~mm}$ is brought in equation (9), the rotation angle $\theta_{5}=24.95^{\circ}$ can be obtained, and the displacement of the rod is $78 \mathrm{~mm}$; the connecting rod variable of the brake joystick is $l_{2}=50 \mathrm{~mm}$ and $l_{3}=400 \mathrm{~mm}, c=10 \mathrm{~mm}$ is brought in equation (9), the rotation angle $\theta_{6}=11.53^{\circ}$ can be obtained, and the displacement of the rod is $55 \mathrm{~mm}$.

The $\mathrm{BC}$ rod length $l_{2}$, the $\mathrm{CD}$ rod length $l_{3}$, the switch stroke $c$, the rotation angle $\theta$, and the theoretical operating force $F$ are substituted into equation (13) to obtain the length $l_{1}$ of each rod handle, and the working variable of each rod are shown in -4 .

\subsubsection{Chinese Adult Male Upper Limb Level Work Area} Design. According to the data and analysis in Tables 2 and 3, the 95th percentile upper limb horizontal operation area in China is obtained, as shown in Figure 12.

As shown in Figure 12, area I is a comfortable manipulation area, the range of which is the envelope area with the shoulder joint as the center and R400 as the radius. Area III is the effective operation area, which is equivalent to the range of upper limb function. Area IV is an expandable operation area, which is defined as the area that can be properly changed (inclined and bent) and the hand can be reached in the correct sitting position. Joystick location layout should meet within the scope of regional III. Surface height should be able to make the person's upper arms naturally prolapse, which is in a state of relaxed and comfortable. Arm should be as far as possible under level or slightly oblique. This will reduce arm soreness. Based on the abovementioned analysis, an ideal relative position of the bars can be obtained, so as to design the overall space layout of the cab.

3.1.3. Design of Cab Maneuvering Space Layout. Combining the data in Tables 2 and 3 with the corrections, the sum of the elbow height and the calf plus foot height of the lower man in the 50th percentile sitting position is $676 \mathrm{~mm}$. Taking into account the amount of shoe and dressing correction $(40 \mathrm{~mm})$, the vertical distance between 
TABLE 4: Design variable and theoretical operating force of the joystick.

\begin{tabular}{|c|c|c|c|c|c|c|c|c|}
\hline No. & The evaluation object & $\begin{array}{l}\text { Length of } \\
\mathrm{AB} 11 / \mathrm{mm}\end{array}$ & $\begin{array}{l}\text { Length of } \\
\text { BC } 12 / \mathrm{mm}\end{array}$ & $\begin{array}{l}\text { Length of } \\
\text { CD 13/mm }\end{array}$ & $\begin{array}{l}\text { Switch } \\
\text { stroke } c \\
(\mathrm{~mm})\end{array}$ & $\begin{array}{l}\text { Rotation } \\
\text { angle } \theta /^{\circ}\end{array}$ & $\begin{array}{l}\text { Displacement of } \\
\text { the } \operatorname{rod} / \mathrm{mm}\end{array}$ & $\begin{array}{c}\text { Theoretical } \\
\text { operating force } \\
\text { F/N }\end{array}$ \\
\hline 1 & $\begin{array}{l}\text { Unloading clutch } \\
\text { operating lever reel } \\
\text { operating lever }\end{array}$ & 280 & 75 & 400 & 10 & 7.66 & 55 & 32.0 \\
\hline 2 & $\begin{array}{c}\text { Forward and backward } \\
\text { operating lever }\end{array}$ & 450 & 45 & 270 & 20 & 26.42 & 182 & 11.55 \\
\hline 3 & Shift lever & 420 & 180 & 680 & 70 & 20.00 & 154 & 43.93 \\
\hline 4 & $\begin{array}{l}\text { Cutting table integrated } \\
\text { joystick }\end{array}$ & 350 & 65 & 410 & 20 & 23.21 & 148 & 21.91 \\
\hline 5 & $\begin{array}{l}\text { Harvesting device } \\
\text { joystick }\end{array}$ & 280 & 95 & 480 & 40 & 18.24 & 78 & 39.34 \\
\hline 6 & Brake lever & 220 & 50 & 400 & 10 & 11.54 & 55 & 27.8 \\
\hline
\end{tabular}

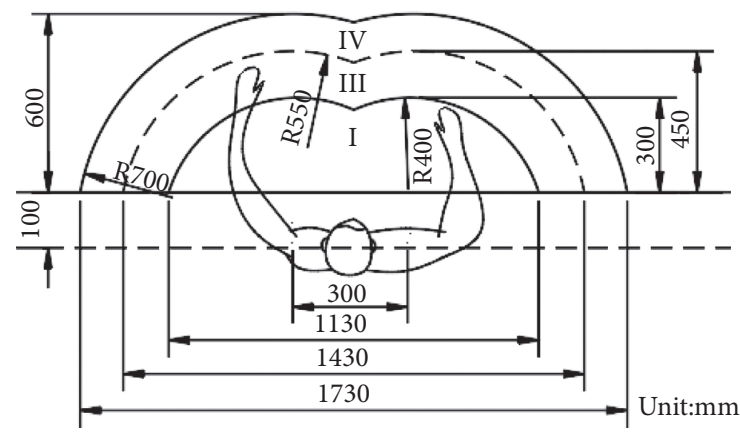

FIGURE 12: Schematic diagram of horizontal working area of man's upper limbs.

the elbow and foot of the 50th percentile man is $716 \mathrm{~mm}$, and the height of the working surface is $500 \mathrm{~mm}$, which is the height of the console. The best height is $178-203 \mathrm{~mm}$ above the $\mathrm{H}$ point ( $\mathrm{H}$ point is the span point), and the vertical height of the lever handle position should be designed to be $100-250 \mathrm{~mm}$ higher than the console. Therefore, the designed reel operating lever is $160 \mathrm{~mm}$ higher than the console. The forward and backward operating lever is $250 \mathrm{~mm}$ higher than the console. The shift lever is $200 \mathrm{~mm}$ above the console. The brake lever is $100 \mathrm{~mm}$ higher than the console.

According to the calculated steering angle of each lever and the specified height of levers higher than the console, the length of the lever stroke groove of the console can be determined. Through calculation, the slot length of the reel operating lever on the console is $40 \mathrm{~mm}$ (the data are rounded and the functional stroke is $33 \mathrm{~mm}$ ). The upper end of the reel operating lever groove makes the reel lower, and the lower end raises the reel. The groove of cutting table integrated joystick is Mi-shaped. In order to simplify the processing, we design the groove to be a circle with a diameter of $85 \mathrm{~mm}$. The left end of the groove turns the harvester left and the right end turns the harvester right, and the upper end makes the header and the lower end raises the header. The length of the forward and backward operating lever groove is $120 \mathrm{~mm}$ (bidirectional, stepped, and the functional stroke is $92 \mathrm{~mm}$ ), the front section of the groove advances the harvester, the middle of the groove stops the harvester, and the rear end of the groove moves the harvester backward. The length of the shift lever groove on the console is $180 \mathrm{~mm}$ (the function stroke is $150 \mathrm{~mm}$ ); the front section of the groove represents the standard speed, and the rear end of the groove represents low speed. The length of the brake lever groove is $145 \mathrm{~mm}$, and the front section of the groove represents the state of small throttle; the rear end of the groove represents the state of large throttle.

The control console in the cab is mainly composed of a side control panel, which is located on the left-hand side of the driver. The central bedplate is located directly in front of the driver. Therefore, the length, width, and thickness of the instrument panel of the central control console are $1100 \mathrm{~mm}, 180 \mathrm{~mm}$, and $2 \mathrm{~mm}$, respectively. The length, width, and thickness of the instrument panel of the measurement and control console are $1200 \mathrm{~mm}, 310 \mathrm{~mm}$, and $2 \mathrm{~mm}$, respectively. After manufacturing the grooves required for the instrument panel and levers, distribute the levers in the normal working area of the driver's left and right hands. Taking the left and right shoulders of the driver as the center of the circle, the radius of $400 \mathrm{~mm}$ is the most suitable area for the distribution of the rods. The rods should not exceed the radius of a circle with the shoulder as the center and a radius of $550 \mathrm{~mm}$. The overall space layout of the designed cab and the internal structure of the bar are shown in Figures 13 and 14 below.

3.1.4. Stress and Strain Analysis of the Chassis Frame. The static analysis is mainly used to analyze the deformation and equivalent stress of the chassis after being loaded. According to the value of the total variables and the equivalent stress on the cloud map, the bearing capacity of each part of the chassis is analyzed [32]. Based on the previous meshing, loading and restraining of the chassis frame, the stress-strain cloud map is obtained as Figure 5.

According to Figure 5(a), it can be seen that the distribution of large stress is concentrated at the connection between the upper frame and the middle frame, the horizontal resistance of the crawler to the frame and the compression part of the grain box. So, the maximum stress is less than $173.25 \mathrm{Mpa}$. There is no stress concentration. The yield strength of Q235 material is $235 \mathrm{Mpa}$, which is meeting the 


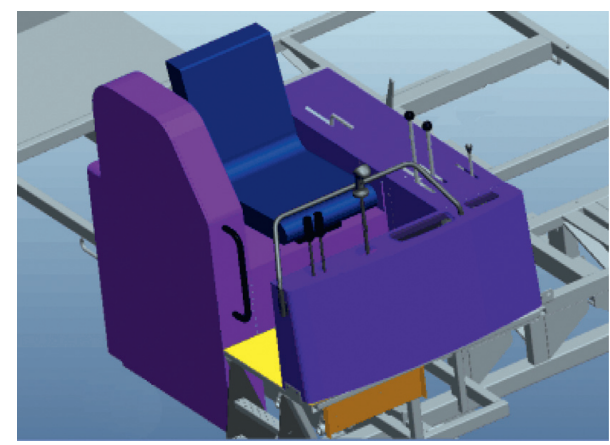

Figure 13: Overall layout model of cab maneuvering space.

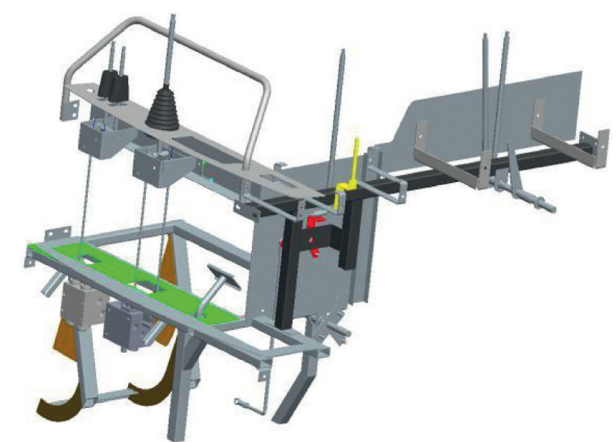

FIGURE 14: Internal structure of the operating lever.

requirements of Q235. According to Figure 5(b), the most serious deformation of the chassis frame is the red part, which is about $9.2504 \mathrm{~mm}$. Because of full load, the bearing part of the grain box is the largest pressure. The supporting beam of the load-bearing part is a cantilever beam structure, where the bending moment is large and the deformation is the most obvious. The second largest part of the deformation is the fuel tank, and the deformation is 1.0278 to $5.1391 \mathrm{~mm}$. This is because the fuel tank is at the farthest edge of the frame, and there is not enough support beams in the longitudinal direction to share the load. The third largest part of the deformation is the cab, and the total deformation is 0 to $5.1391 \mathrm{~mm}$. This is because the entire bridge support is also in a suspended state, with insufficient support, resulting in a relatively large deformation. So, when the total weight is about $4 \mathrm{t}$ in full load, the maximum shape variable is $9.2504 \mathrm{~mm}$. The strength and stiffness of the chassis frame meet the design requirements.

\subsection{Physical Assembly and Production}

3.2.1. Integral Assembly of Mechanical Model. From the perspective of the overall configuration of the whole machine, the cab is placed above the frame of crawler on the right side of the crawler chassis. The space adjustment of each solid module is carried out to ensure reasonable space configuration and balanced center of gravity configuration of the whole machine. The integral assembly of crawler chassis is shown in Figure 15.
3.2.2. Production of Test Prototype. According to the variable shown in Tables 2, 3, and 5, each device was developed and manufactured in Dongfeng agricultural machine Co., Ltd. The chassis frame is welded with square and rectangular pipes of different specifications such as $30 \times 30 \mathrm{~mm}$, $40 \times 40 \mathrm{~mm}$, and $40 \times 60 \mathrm{~mm}$. The chassis frame is $3.807 \mathrm{~m}$ long, $2.163 \mathrm{~m}$ wide, and $1.036 \mathrm{~m}$ high. The suspension plate width of the rubber track is $340 \mathrm{~mm}$. The grounding length is $1700 \mathrm{~mm}$. The total length is $3900 \mathrm{~mm}$. The full-load average grounding pressure ratio is $33.9 \mathrm{kpa}$. The size of the cab is $1400 \times 1100 \times 1350 \mathrm{~mm}$, which is placed above the track on the right side of the chassis frame to complete the overall assembly. The actual picture of crawler chassis of rice combine harvester is shown in Figure 16.

\subsection{Comparative Analysis of Theoretical Design and Experimental Results}

3.3.1. Joystick Design and Control Force Test. The operating force of the operating lever was tested with four times. The mean value was taken as the actual operating force, with the least significant difference being less than 0.05 . The operating forces of operating levers were shown in Figure 17. In order to facilitate comparison and analysis with theoretical values, the test values of various power capabilities of each operating lever are taken as the average value of the actual operating force of the operating lever as a whole. The theoretical values was compared with experimental results, and the results were shown in Figure 17.

According to Figure 17, in addition to the forward and backward operating lever and the harvesting device joystick, the average operating force of the various types of levers designed in this paper is between $30.36 \mathrm{~N}$ and $42.71 \mathrm{~N}$. Based on the 95th percentile of Chinese adult male hand, the best operating force is between $30 \mathrm{~N}$ and $40 \mathrm{~N}$, so the actual lever operating force is in line with the ergonomics check. Since the forward and backward operating lever slot is stepped, the action is divided into two steps. The operating force should be appropriately reduced. Therefore, the actual average operating force is $13.19 \mathrm{~N}$, which is in line with actual needs. The harvesting device joystick controls the operation and stop of the whole machine. In order to improve the fault tolerance of the machine and prevent the rice combine harvester from being stopped due to improper operation, the operating force should be appropriately designed to be larger. So, the actual operating force of $72.36 \mathrm{~N}$ is also in line with the actual demand.

In addition to the cutting table integrated joystick and the harvesting device joystick, the operating force error of the remaining joystick members is $0.69 \%$ of the unloading grain and the reel lever. The maximum operating force is the forward and backward operating lever of $12.23 \%$. It can be seen that the actual value of the lever is more in line with the theoretical design value. According to Table 1, the utilization rate of the harvesting device is low. The design priority is only in the fifth, so the design error of the member is affordable. The design results of the joystick in this paper are reliable and achieve the expected results. The operating force 


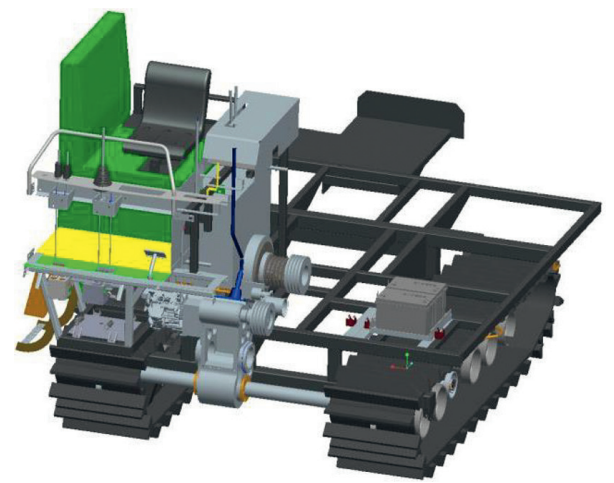

FIGURE 15: Integral assembly of crawler chassis.

TABLE 5: Main component variable of the combine harvester.

\begin{tabular}{|c|c|c|c|c|c|c|c|}
\hline Main load & Grain box & $\mathrm{Cab}$ & Engine & Oil tank & Cylinder & Threshing drum & Battery \\
\hline Working weight (kg) & 1771 & 265 & 300 & 85 & 359.4 & 1260 & 50 \\
\hline Bearing area $\left(\mathrm{m}^{2}\right)$ & 0.0560 & 0.1760 & 0.0264 & 0.1350 & 0.0142 & 0.1585 & 0.0154 \\
\hline Intensity of full-load pressure (MPa) & 0.3098 & 0.0150 & 0.1040 & 0.0617 & 0.2480 & 0.0779 & 0.0319 \\
\hline Allowable load $(\mathrm{N})$ & 20826.96 & 3116.4 & 3528 & 999.6 & 4226.88 & 14817.6 & 588 \\
\hline
\end{tabular}

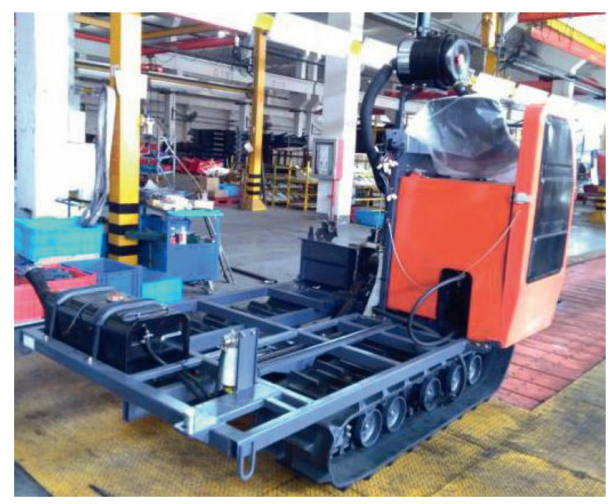

Figure 16: Production of crawler chassis of the combine harvester.

of the joystick is suitable for the best operating force of the 95th percentile adult male in China.

3.3.2. Bearing Stability of Crawler Chassis. The caterpillar chassis frame of the combine harvester is equipped with model combine harvester, which was developed and manufactured in Dongfeng agricultural machine Co., Ltd. The weight of the crawler chassis is $1500 \mathrm{~kg}$. The test site was located in Changzhou town (119.93 N, 31.72 W), which is located in China's southeast. The mean annual temperature and precipitation were $15.5^{\circ} \mathrm{C}$ and $1226 \mathrm{~mm}$, respectively. The test pavement for the crawler chassis is a cement pavement. The test speed is three grades, which are $1 \mathrm{~m} / \mathrm{s}$, $1.5 \mathrm{~m} / \mathrm{s}$, and $2 \mathrm{~m} / \mathrm{s}$. In order to verify the stability of the processed crawler chassis under high load, it is necessary to test the straight speed of the harvester on the cement road surface. In addition, in order to simulate the actual movement of the harvester after bearing load, we adopt the method of gradually adding counterweights to the chassis frame of the harvester to make the chassis frame bear $4 \mathrm{t}$. The combine harvester performs the straight line driving ability test on the cement road surface, as shown in Figure 18.

Three grades' test speed was carried out for each gear position and the driving time was recorded. The test data of each gear are shown in Table 6.

The travel time is converted to the travel speed at high load, as shown in Table 7. According to the experimental data in Tables 6 and 7, the bearing stability of the crawler chassis designed in this paper is analyzed. The rice combine harvester equipped with the crawler self-propelled chassis designed in this paper was obtained.

According to Tables 6 and 7, the average running speed of the harvester on the cement pavement is $0.9 \mathrm{~m} / \mathrm{s}, 1.4 \mathrm{~m} / \mathrm{s}$, and $1.85 \mathrm{~m} / \mathrm{s}$, respectively. The test data show that the gearbox is in actual operation. The transmission efficiency is 


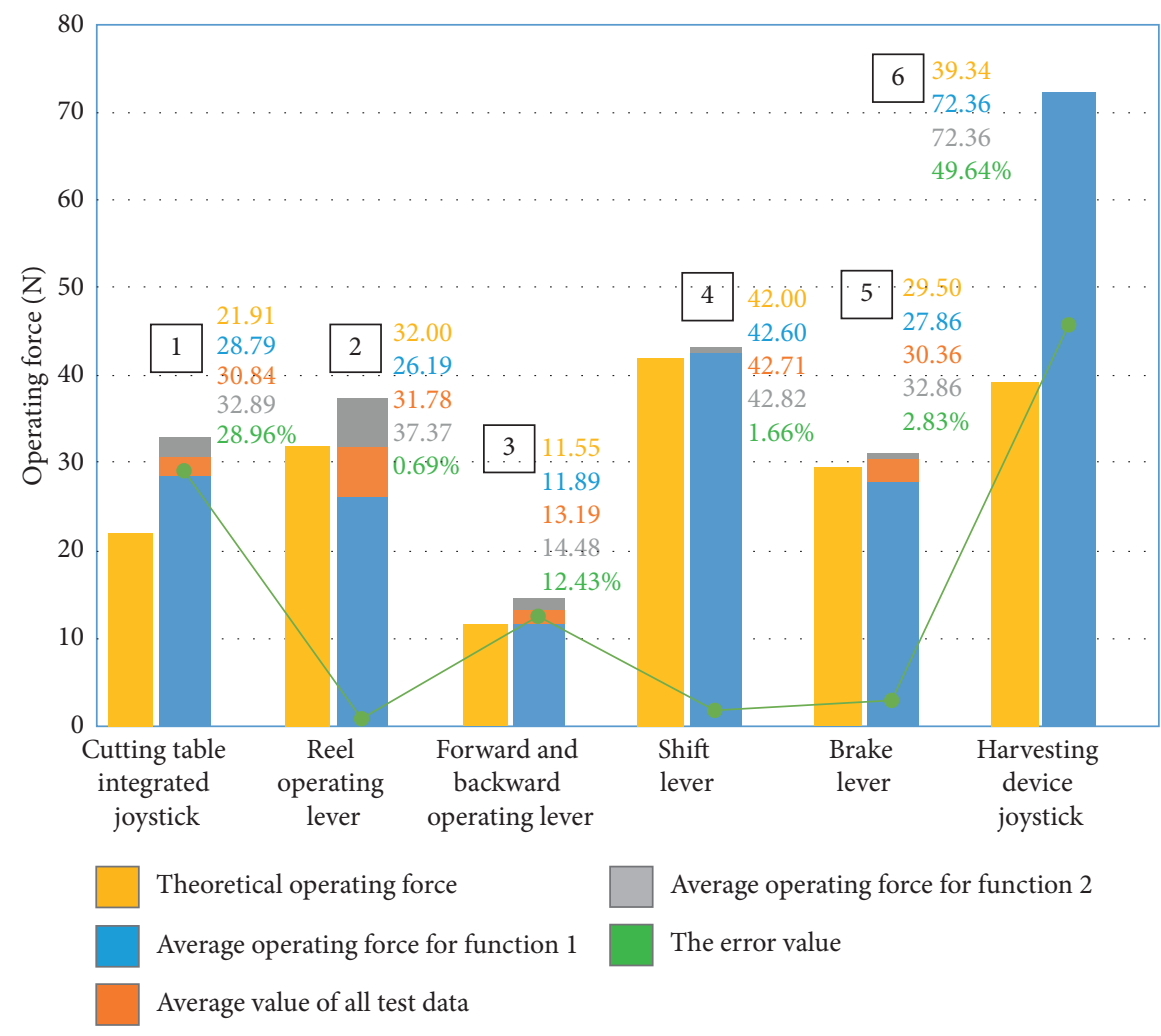

FIGURE 17: Comparison between theoretical operating force and actual operating force.

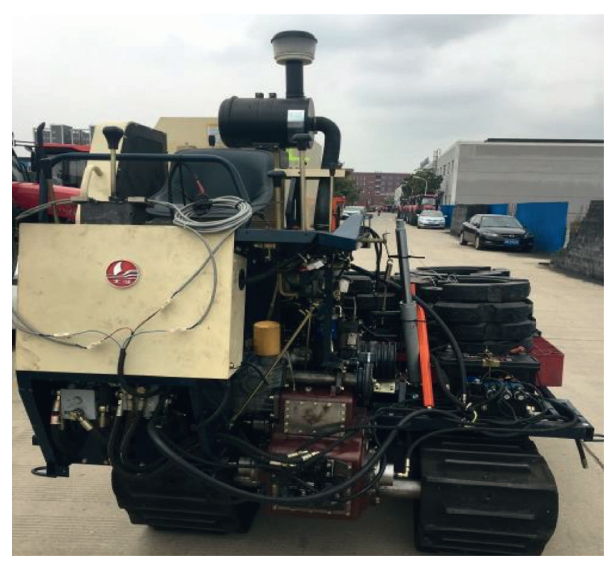

FIGURE 18: Bearing stability test of the crawler chassis of the combine harvester.

TABLE 6: Rice combine harvester straight travel time (s).

\begin{tabular}{lcccccccc}
\hline No. & 1 & 2 & 3 & 4 & 5 & Mean value/s & Variance & Standard deviation \\
\hline First gear $(1 \mathrm{~m} / \mathrm{s})$ & 55.65 & 55.72 & 55.34 & 55.60 & 55.43 & 55.53 & 0.1015 & 0.3186 \\
Second gear $(1.5 \mathrm{~m} / \mathrm{s})$ & 35.78 & 35.55 & 35.71 & 35.30 & 35.65 & 35.60 & 0.1395 & 0.3735 \\
Third gear $(2 \mathrm{~m} / \mathrm{s})$ & 27.12 & 26.86 & 27.15 & 26.81 & 26.95 & 27.03 & 0.1062 & 0.3259 \\
\hline
\end{tabular}

TABLE 7: High-load linear speed of the combine harvester.

\begin{tabular}{lcccccccc}
\hline No. & 1 & 2 & 3 & 4 & 5 & Mean value $(\mathrm{m} / \mathrm{s})$ & Variance & Standard deviation \\
\hline First gear $(1 \mathrm{~m} / \mathrm{s})$ & 0.898 & 0.897 & 0.904 & 0.899 & 0.902 & 0.900 & $2.668 \times 10^{-5}$ & 0.0052 \\
Second gear $(1.5 \mathrm{~m} / \mathrm{s})$ & 1.397 & 1.406 & 1.400 & 1.416 & 1.403 & 1.404 & $2.189 \times 10^{-4}$ & 0.0148 \\
Third gear $(2 \mathrm{~m} / \mathrm{s})$ & 1.844 & 1.862 & 1.841 & 1.865 & 1.855 & 1.850 & $5.022 \times 10^{-4}$ & 0.0224 \\
\hline
\end{tabular}


about $90 \%$ to $93 \%$ of the design calculation. The load capacity of the crawler chassis can meet the expected requirements. The whole machine can be stably operated with the condition of load $4 \mathrm{t}$. The speed variance is close to 0 , which is generally satisfied with test requirements.

\section{Conclusions}

(1) The results of stress-strain cloud diagram obtained by Finite Element Analysis show that under the lowspeed full-load condition, the maximum strain of the chassis frame is the load-bearing part of the grain box. The load-bearing part of the oil tank has a shape variable of $1.0278 \sim 5.1391 \mathrm{~mm}$, which are all within a reasonable controllable range. The stress distribution is concentrated at the joint between the upper frame and the middle frame, the horizontal resistance of the track to the frame, and the pressure of the grain box. The maximum stress is less than $173.25 \mathrm{MPa}$. The strength is checked and meets the design requirements.

(2) When the designed track grounding length is $1.7 \mathrm{~m}$, the steering ratio is 1.185 and the crawler chassis is $4 \mathrm{t}$; it is applied to the rice combine harvester at the first speed of $1 \mathrm{~m} / \mathrm{s}, 1.5 \mathrm{~m} / \mathrm{s}$, and $2 \mathrm{~m} / \mathrm{s}$. The driving test results show that the maximum variance of the combine harvester speed is $5.022 \times 10^{-4}$. The maximum standard deviation is 0.0224 , which indicates that the crawler chassis still has good driving stability and good carrying performance at high load.

(3) The test results of man-machine test show that the average operating force of all kinds of operating levers designed in this paper is between $30.36 \mathrm{~N}$ and $42.71 \mathrm{~N}$, which meets the best operating force of the hands of adult males in the 95th percent in China. The operating force test value of the forward and backward lever is $13.19 \mathrm{~N}$, which is designed to match its stepped groove. The experimental value of joystick is to improve the fault tolerance rate of the rice combine harvester operated by the hand, so the operating force is in line with the ergonomic design. The operation force error is small, which is reasonable and reliable.

\section{Data Availability}

The data used to support the findings of this study are available from the corresponding author upon request.

\section{Conflicts of Interest}

The authors declare that they have no conflicts of interest.

\section{Acknowledgments}

This research work was supported by the Natural Science Foundation of Jiangsu Province (BK20170553), Jiangsu Province "Six Talents Peak" High-level Talent Project (GDZB-085), Open Fund of Jiangsu Key Laboratory of Agricultural Equipment and Intelligent High Technology
(JNZ201912), Jiangsu University 2019 College Students Practice Innovation Training Program Project (201910299030Z), Funding project of Jiangsu University for scientific research projects (18A328), and A Project Funded by the Priority Academic Program Development of Jiangsu Higher Education Institutions (PAPD-2018-87).

\section{References}

[1] Z. Tang, Y. Li, X. Li, and T. Xu, "Structural damage modes for rice stalks undergoing threshing," Biosystems Engineering, vol. 186, no. 1, pp. 323-336, 2019.

[2] Z. Tang, H. Zhang, H. Li et al., "Developments of crawler steering gearbox for combine harvester straight forward and steering in situ," International Journal of Agricultural and Biological Engineering, vol. 13, no. 1, pp. 120-126, 2020.

[3] R. F. Shen, J. H. Liu, and Z. L. Fu, "Trafficability of the caterpillar harvester," Journal of Fujian Agricultural and Forestry University, vol. 39, no. 1, pp. 98-101, 2010.

[4] M. Sojka and S. Cornak, "Mathematical model of suspension of tracked vehicles," in Proceedings of the 2017 International Conference on Military Technologies (ICMT), pp. 111-114, IEEE, Brno, Czech Republic, May 2017.

[5] P. Y. Liu, Z. J. Wang, H. T. Li et al., "design and overcoming obstacles ability research of tracked driving chassis with planetary structure," Transactions of the Chinese Society for Agricultural Machinery, vol. 45, pp. 17-23, 2014.

[6] S. P. Sutisna, R. P. A. Setiawan, I. D. M. Subrata et al., "System identification and steering control characteristic of rice combine harvester model," IOP Publishing:Earth and Environmental Science, vol. 147, no. 1, Article ID 012020, 2018.

[7] X. R. Lü and X. L. Lü, "Design of a new crawler chassis brake system," Applied Mechanics and Materials, vol. 635-637, pp. 1224-1227, 2014.

[8] Y. M. Li, J. S. Chen, Z. W. Liang et al., "Design and experiment of differential steering mechanism for track combine harvester," Transactions of the Chinese Society for Agricultural Machinery, vol. 47, no. 7, pp. 127-135, 2016.

[9] B. Li, D. Sun, M. Hu, and J. Liu, "Automatic starting control of tractor with a novel power-shift transmission," Mechanism and Machine Theory, vol. 131, pp. 75-91, 2019.

[10] Y. Xia and D. Sun, "Characteristic analysis on a new hydromechanical continuously variable transmission system," Mechanism and Machine Theory, vol. 126, pp. 457-467, 2018.

[11] R. N. Lidiane and A. C. Joao, "Technology transfer and anthropotechnology: an analysis of the sugarcane harvesting in Australia and Brazil," African Journal of Agricultural Research, vol. 13, no. 31, pp. 1564-1576, 2018.

[12] B. Qiu, J. Zhou, Z. Zheng et al., "A user satisfaction survey for Chinese tractors based on attitude index of product attributes," Advances in Intelligent Systems and Computing, Springer, New York, NY, USA, pp. 337-349, 2017.

[13] C. J. Han, Y. Liu, X. L. Zhu, and X. J. Zhang, "Design and test of edible sunflower plate harvester base on reciprocating lever," Journal of Agricultural Mechanization Research, vol. 3, p. $25,2018$.

[14] B. S. Lee, S. Yoo, C. Lee et al., "Prototype development of a small combine for harvesting miscellaneous cereal crops and its basic performance," Journal of Biosystems Engineering, vol. 43, no. 4, pp. 311-319, 2018.

[15] J. W. Wang, Y. R. Wang, X. S. Li et al., "Ergonomic design of driving comfort in combine harvester cab," Journal of Northeast Agricultural University, vol. 3, pp. 97-103, 2014. 
[16] F. Wang, L. Yang, S. Y. Xie et al., "Design and research of a powered chassis of a triangle track orchard," Journal of Agricultural Mechanization Research, vol. 41, no. 5, pp. 97-102, 2019.

[17] Z. Tang, B. Zhang, H. Q. Zhu, D. Liu, and Y. Li, "Reliability test and fatigue analysis of multi-stage transmission gears of crawler combine harvester chassis gearbox," International Agricultural Engineering Journal, vol. 28, no. 3, pp. 160-169, 2019.

[18] T. Zhang, G. F. Yue, and W. Liu, "Research progress of rubber crawler chassis," Journal of Chongqing University of Technology(Natural Science), vol. 32, no. 380, pp. 88-94, 2018.

[19] Z. B. Jin, B. Huang, J. J. Ren et al., "Reduction of vehicleinduced vibration of railway bridges due to distribution of axle loads through track," Shock and Vibration, vol. 2018, Article ID 2431980, 14 pages, 2018.

[20] Y. J. Qi, Z. G. Sun, Y. Ma et al., "Design analysis and experimental research on the walking system of small tracked tractor," Journal of Agricultural Mechanization Research, vol. 40, no. 1, pp. 228-233, 2018.

[21] Z. H. Zhao, X. H. Mu, H. L. Guo et al., "Static grounding pressure test and modeling of rubber track wheel," Transactions of the Chinese Society of Agricultural Engineering, vol. 34, no. 3, pp. 72-79, 2018.

[22] K. W. Ye, S. D. Wei, and H. Bao, "Hand operation research for cockpit layout optimization," Mechanical Science and Technology, vol. 37, no. 279, pp. 97-102, 2018.

[23] Y. C. Miao, R. X. Kang, and X. F. Chen, "Reliability evaluation and improvement approach of chemical production manmachine-environment system," IOP Conference Series: Materials Science and Engineering, vol. 274, no. 1, Article ID 012004, 2017.

[24] M. Z. Liu, W. W. Zhou, D. W. Zhang et al., "Vector description and cluster Analysis of vehicle handling joy comfort," Automotive Engineering, vol. 35, no. 6, pp. 521-525, 2013.

[25] X. Y. Yan, E. R. Mao, Z. X. Zhu et al., "Evaluation method of human-machine interface in the cab of combine harvester," Transactions of the Chinese Society of Agricultural Machinery, vol. 41, no. 10, pp. 91-96, 2010.

[26] Z. Tang, Y. M. Li, and L. Z. Xu, "Operating lever design on driving console of convertible crawler combine harvester," International Agricultural Engineering Journal, vol. 25, no. 4, pp. 122-130, 2016.

[27] C.-C. Huang and S. T. Yabiku, "Digital divide and body size disparities among Chinese adults," Demographic Research, vol. 38, pp. 109-126, 2018.

[28] Q. H. Liu, Y. Ren, and P. Wang, "Thinking on the design of wheeled self-propelled combine harvester chassis," China Science and Technology Investment, vol. 27, p. 267, 2017.

[29] L. Zheng, H. Zhou, Y. Zeng et al., "Static analysis and structural improvement of chassis frame of a tracked harvester," Mechanical Design \& Manufacture, vol. 3, pp. 228232, 2017.

[30] L. Zhao, H. Liu, and W. Zhou, "A study on the dynamic transmission law of spiral drum cutting coal rock based on ANSYS/LS-DYNA simulation," Complexity, vol. 2019, Article ID 1482051, 14 pages, 2019.

[31] J. H. Bucklow, R. Fairey, and M. R. Gammon, "An automated workflow for high quality CFD meshing using the 3D medial object," in Proceedings of the 23rd AIAA Computational Fluid Dynamics Conference, AIAA, Denver, Colorado, p. 3454, June 2017.
[32] Z. G. Cao, M. M. Liu, and P. C. Wu, "Experiment investigation and numerical simulation of snowdrift on a typical large-span retractable roof," Complexity, vol. 2019, Article ID 5984804, 14 pages, 2019. 